\title{
Nutritional Value and Associated Potentials Risks of Seafood Consumption
}

\section{Mohiuddin AK* \\ Department of Pharmacy, World University of Bangladesh, Bangladesh}

*Corresponding author: Abdul Kader Mohiuddin, Department of Pharmacy, World University of Bangladesh, 151/8, Green Road, Dhanmondi, Dhaka-1205, Bangladesh, Tel: +8801716477485; Email: mohiuddin3@pharmacy.wub.edu.bd

\section{Short Communication}

Volume 4 Issue 3

Received Date: July 11, 2019

Published Date: July 18, 2019

DOI: $10.23880 /$ act-16000159

\begin{abstract}
Seafood provides essential nutrients to the body. A study funded by CDC found that eating seafood for essential Omega-3 fatty acids can prevent 84,000 deaths each year. According to a Harvard study, 3-ounce servings of fatty fish a week reduces the risk of dying from heart disease by nearly 40\%. Eating 8 two servings of fish per week during pregnancy can improve baby's IQ, cognitive development, and eye health. Older adults with the highest fish consumption live and average of 2.2 years longer. But all these statements possess another side of the coin. Food-born poisoning, mercury-leadarsenic-cadmium poisoning, exposure to polycyclic aromatic hydrocarbons (PAHs) raised the issue of safety with aberrant consumption of seafoods. Seafood choices that are very low in mercury include: salmon, sardines, pollock, flounders, cod, tilapia, shrimp, oysters, clams, scallops and crab. The U.S. Food and Drug Administration (FDA) and Environmental Protection Agency (EPA) have developed the following advice to help consumers minimize risks that could be associated with mercury in seafood.
\end{abstract}

Keywords: Nutritional Value; Environmental Protection; Aquaculture Production; Seafood

\section{Discussion}

Global seafood trade nearly doubled in recent decades with demand steadily increasing, fueled by decreasing transportation costs, advances in preservation and processing technologies, and open trade policies and is now among the most highly traded commodities [1-8]. A nearly $40 \%$ of seafood consumed in the US is of domestic origin [9]. Fried seafood accounted for 1 in 5 seafood meals and $30 \%$ of total seafood calories in the US in 200514 [10]. The top species consumed in Mexico were: canned tuna, sunfish, shrimp, mullet, carp and schoolshark (constituted $60 \%$ of seafood intake) [11]. Seafood consumption is rising above 20.0 kilo per capita per year on a global average and over 22.0 kilo Europe [12]. Habitual intake of marine fish and seafood, such as microalgae, which are very rich in some chemical compounds, has been strongly associated with several benefits in human health [13]. Encouraging people to eat more seafood can offer a direct, cost-effective way of improving overall health outcomes [14]. Seafood contains functional components that are not present in terrestrial organisms. Seafood, such as fish, crustacean and molluscan shellfish, and echinoderms, provides in the edible part (e. g., filet, abdominal muscle) many 
nutritional components beneficial for the human diet like n-3 polyunsaturated long chain fatty acids (PUFAs), namely Eicosapentaenoic acid (EPA) and docosahexaenoic acid (DHA), essential elements such as selenium and iodine, high potassium and low sodium concentrations, and the vitamins $\mathrm{D}, \mathrm{A}, \mathrm{E}$, and $\mathrm{B}(12)$, as well as taurine (2-aminoethanesulfonic acid) among others [15,16]. The Recommended Intake (RI) for EPA+DHA and was associated with a healthier lifestyle [17]. Furthermore, in a recent Norwegian epidemiological study, lean-fish consumption once a week or more was associated with decreased postprandial triacylglycerol (TAG) and increased high-density lipoprotein cholesterol (HDL-C) levels, and in men a decreased waist circumference and blood pressure were identified [18]. Oyen, et al. reported that intake of lean fish was associated with decreased risk of T2DM [19]. Selenium (Se) content of sea fish reduces methylmercury (MeHg) toxicity [20]. Rimm, et al. concluded that 1 to 2 seafood meals per week be included to reduce the risk of congestive heart failure, coronary heart disease, ischemic stroke, and sudden cardiac death, especially when seafood replaces the intake of less healthy foods [21]. Also, Zhao, et al. concluded that fish consumption was associated with a decreased risk of stroke [22]. The PUFAs particularly concentrate in the nervous system, alter immune system function reduce serum triglyceride levels and have been reported to reduce the risk of sudden death after a myocardial infarction [23]. Several meta-analyses have evaluated the beneficial role of LC $\omega$ 3 PUFA supplementation in several mental disorders such as bipolar disorder, schizophrenia, or depression [24]. Yang, et al. 2018 further stated a modest inverse association between fish or omega- 3 fatty acid intake and risk of depression, especially in women [25].

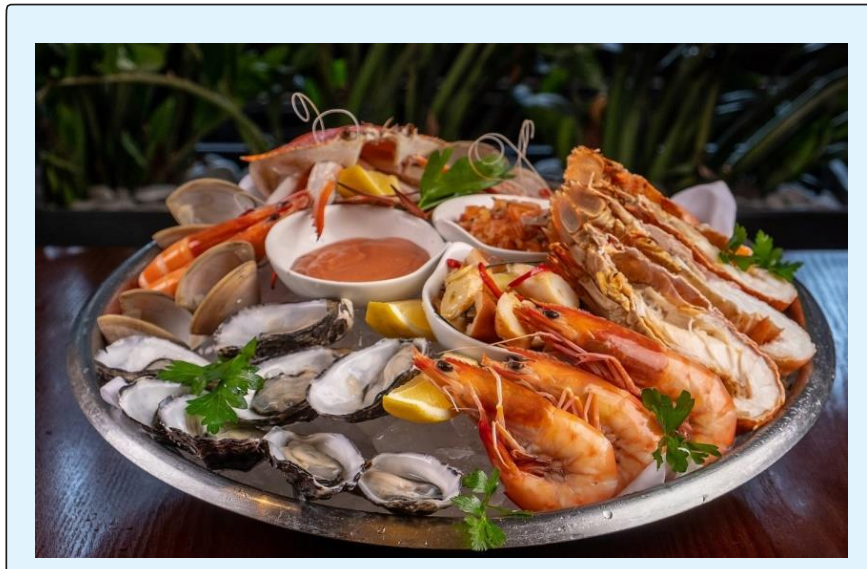

Figure: Seafood platter (Source: Yummy.ph).
Greater consumption of fish is associated with a lower risk of dementia [26]. Weight-loss diet including oily fish resulted in greater TG reduction than did a diet without fish or fish oil [27]. A high intake of fatty seafood increases circulating levels of the insulin-sensitizing hormone adiponectin, whose blood concentration is reduced in obesity and T2DM $[28,29]$. Increased intake of protein from meats, chicken with skin and regular cheese was associated with weight gain but increased intake of seafood together with peanut butter, walnuts, other nuts, chicken without skin, yogurt and low-fat cheese was associated with weight reduction [30]. A frequent intake of lean seafood, as compared with intake of terrestrial meats, reduces energy intake typically in the range of 49\% [29]. Bodybuilders traditionally have chosen many types of seafood (scallops, shrimp, crab, haddock, cod, pollack, snapper, halibut and white tuna) as their prime sources of fairly-digesting protein [31,32]. Adding more seafood to the diet could help get couples' sex lives, and even their fertility. Research suggests that seafood intake might affect semen quality, ovulation or embryo quality [33]. Greater male and female seafood intake were associated with a higher sexual intercourse frequency (SIF) and fecundity among a large prospective cohort of couples attempting pregnancy [34]. In the Norwegian Mother and Child Cohort Study, seafood intake was positively associated with birth weight [35]. However, with the increase in the demand for fish and seafood, aquaculture production is increasing, which could lead to new risks that will need to be addressed in the future to control foodborne pathogens. Fresh fish and seafood are highly perishable, and microbiological spoilage is one of the important factors that limit their shelf life and safety. Fresh seafood can be contaminated at any point from rearing or harvesting to processing to transport or due to cross-contamination by consumer mishandling at home [36]. In response to the BP oil spill of 2010, US FDA warranted risk criteria to protect vulnerable populations from exposure to polycyclic aromatic hydrocarbons (PAHs) through seafood consumption [37]. Most fish have at least some degree of chemical contamination with methylmercury, (which binds to muscle) and/or with persistent organic pollutants such as dioxins, polychlorinated biphenyls, polybrominated diphenyl ethers, chlorinated pesticides (which concentrate in fish fat) [23]. Higher MeHg risk was associated with blue shark and boiled and grilled tuna consumption. For tuna, however, high Se content after boiling and grilling may mitigate MeHg risk [20]. It was suggested that the most at risk group are women of childbearing age and children who should keep mercury intake below $0.2 \mathrm{ug} / \mathrm{kg}$ body weight per day [38]. Rahmani, et al. 2018 concluded canned tuna fish consumed in Iran has not at non- 


\section{Advances in Clinical Toxicology}

carcinogenic risk but has a carcinogenic risk due to arsenic (As) [39].

In North Sea and Port Açu (Brazil) coastal areas, high arsenic (As) concentrations were observed in water, soil and sediments. Lifetime Cancer Risk values at the actual global seafood consumption rate of $54 \mathrm{~g}$ day- 1 are above 10-4 for whelks, scallops, dogfish, ray and lemon sole [40]. A 2-fold increase in fecal trimethylamine (trimethylamine $\mathrm{N}$-oxide, TMAO, a canonical metabolite from gut flora, has been related to the risk of cardiovascular disorders) excretion was observed after the lean-seafood diet period [41]. TMAO levels were highly associated with diabetes in CHD patients [42]. Data for 2015 estimate EU mollusc production at approximately 879,000 tonnes, with 629,000 tonnes (72\%) farmed and the remaining 250,000 tonnes (28\%) wild-caught. Molluscs comprise approximately $11 \%$ of EU seafood consumption. Mussels are the most consumed mollusc species by EU consumers, followed by scallops and then clams. The EU provides comprehensive regulations covering various general food safety aspects to manage the risk of contamination in shellfish farms [43]. Microalgal species growing in marine and aquaculture environments can be responsible for harmful events because of their ability to produce potent natural toxins that can accumulate in edible mollusc species. Their consumption can cause severe illness and even be lethal [44]. A paralytic shellfish poisoning (PSP) event in New England caused estimated losses of $\$ 12$ to $\$ 20$ million in Massachusetts alone, with additional losses in New Hampshire and Maine. Continual PSP intoxication in Alaskan shellfish was estimated to be worth $\$ 6$ million annually [45]. Okadaic acid, azaspiracid, pectenotoxin, gymnodimine, and spirolide-- all these toxins were present in most coastal areas of China at almost all times of the year, which shows that they are a major potential threat to human health [46]. In general, hydrophilic toxins (domoic acid, paralytic shellfish poisoning toxins and tetrodotoxins) showed higher bio-accessibility than lipophilic ones (okadaic acid and azaspiracids).

The bio-accessibility of toxins from the okadaic acid group ranged from 69\% (raw European razor clams) to $74 \%$ (raw donax clams). Regarding azaspiracids, $47 \%$ of the initial content was bio-accessible in steamed blue mussel. As for hydrophilic toxins, $100 \%$ of the initial content was bio-accessible after digestion in raw shellfish and puffer fish gonads [47]. There is, however, a rising concern over the vulnerability of seafood supply chains to species mis-labelling and fraud. DNA methods have been widely used to detect species mis-labelling and a recent meta-analysis of 4500 seafood product tests from 51 publications found an average of 30\% were not the species stated on the label or menu [48]. Although, studies are concentrated in North America, Europe, and Asia.

Elsewhere, including countries in the Middle East and North Africa, studies of this sort are scarce [49]. Over time, plastic particles contaminate the marine ecosystem and the food chain, including foodstuffs intended for human consumption [50]. Global seafood trade in 2016 was $\$ 132.6$ billion, and over $90 \%$ of US seafood was imported from geographic regions with significant waste leakage and pelagic plastic pollution [51]. Humans can be exposed to microplastics through the consumption of seafood, can cause histopathological changes, may affect growth, the reproduction system, and behavior [52]. Ergonomic and safety solutions should be implemented to prevent musculoskeletal injuries/illnesses in seafood processing [53]. In the UK, pregnant women are recommended to consume no more than two $140 \mathrm{~g}$ portions of fatty fish per week [54]. Although, Amezcua, et al. concluded that an average seafood intake of at least $29 \mathrm{~g} /$ day during pregnancy, equivalent to 2-3 servings/week, reduced the risk of $\mathrm{n}$ small for gestational age (SGA) newborn, compared with an average seafood intake of less than $8 \mathrm{~g} /$ day [55]. The carcinogenic risk (CR) index indicated that $\mathrm{Cd}$ and $\mathrm{Pb}$ in the muscles of selected shellfish (Portunus reticulatus, P. segnis, P sanguinolentus, Scylla olivaceae, Penaeus monodon, and P. indicus) species caused the greatest cancer risk [56]. Anisakiasis (fish-borne parasitic disease caused by consumption of raw or undercooked fish) from herring, cod, squid, mackerel consumption is common in countries with high-fish consumption, such as Japan (20,000 cases are reported annually) [57].

Ciguatera Fish Poisoning (CFP) is the most frequently reported seafood-toxin illness in the world. CFP is not due to the mishandling of fish and is not prevented by any particular storage, preparation, or cooking methods [58]. So many issues of the same are discussed in many articles in PubMed, ALTAVISTA, Embase, Scopus, Web of Science, and the Cochrane Central Register. At the end, lean fish should be included in the diet when targeting the modifiable risk factors that are comprised in metabolic syndrome [59]. Seafood is an easily perishable food due to its chemical composition. Immediately after harvest, changes in odor, taste, and texture in fishery products can be noticed. For this reason, measures to protect the product must be taken immediately after harvest or catching [60]. Ocean acidification and warming may threaten future seafood production, safety and quality by negatively impacting the fitness of marine species. Identifying changes in nutritional quality, as well as 


\section{Advances in Clinical Toxicology}

species most at risk, is crucial if societies are to secure food production [61].

\section{References}

1. Gomez-Candela C, Roldan Puchalt MC, Palma Milla S, Lopez Plaza B, Bermejo L (2015) The Role of Omega-3 Fatty Acids in Diets. J Am Coll Nutr 34(1): 42-47.

2. Danaei G, Ding EL, Mozaffarian D, Taylor B, Rehm J, et al. (2009) The preventable causes of death in the United States: Comparative risk assessment of dietary, lifestyle, and metabolic risk factors. PLoS Med 6(4).

3. Mozaffarian D, Rimm EB (2006) Fish intake, contaminants, and human health: evaluating the risks and the benefits. JAMA 296(15): 1885-1899.

4. Zhang AC, Downie LE (2019) Preliminary Validation of a Food Frequency Questionnaire to Assess LongChain Omega-3 Fatty Acid Intake in Eye Care Practice. Nutrients 11(4).

5. Starling P, Charlton K, McMahon AT, Lucas C (2015) Fish intake during pregnancy and foetal neurodevelopment--a systematic review of the evidence. Nutrients 7(3): 2001-2014.

6. Razzaghi H, Tinker SC (2014) Seafood consumption among pregnant and non-pregnant women of childbearing age in the United States, NHANES 19992006. Food Nutr Res 11(58).

7. Mozaffarian D, Lemaitre RN, King IB, Song X, Huang H, et al. (2013) Plasma phospholipid long-chain $\omega-3$ fatty acids and total and cause-specific mortality in older adults: a cohort study. Ann Intern Med 158(7): 515-525.

8. Gephart JA, Pace ML (2015) Structure and evolution of the global seafood trade network. Environ Res Lett 10: 125014 .

9. Gephart JA, Froehlich HE, Branch TA (2019) Opinion: To create sustainable seafood industries, the United States needs a better accounting of imports and exports. Proc Natl Acad Sci USA 116(19): 9142-9146.

10. Kantor L, Lin BH (2019) Intake of Fried Fish at Home and Away from Home in the United States Using Nationally-Representative Data from WWEIA, 200514 (P04-192-19). Curr Dev Nutr 3(1): 1-1.
11. Cantoral A, Batis C, Basu N (2017) National estimation of seafood consumption in Mexico: Implications for exposure to methylmercury and polyunsaturated fatty acids. Chemosphere174: 289296.

12. Richter IGM, Klockner CA (2017) The Psychology of Sustainable Seafood Consumption: A Comprehensive Approach. Foods 6(10).

13. Gammone MA, Gemello E, Riccioni G, D'Orazio N (2014) Marine bioactives and potential application in sports. Mar Drugs 12(5): 2357-2382.

14. Farmery AK, O'Kane G, McManus A, Green BS (2018) Consuming sustainable seafood: guidelines, recommendations and realities. Public Health Nutr 21(8): 1503-1514.

15. Hosomi R, Yoshida M, Fukunaga K (2012) Seafood consumption and components for health. Glob J Health Sci 4(3): 72-86.

16. Oehlenschlager J (2012) Seafood: nutritional benefits and risk aspects. Int J Vitam Nutr Res 82(3): 168-176.

17. Marushka L, Batal M, Sadik T, Schwartz H, Ing A, et al. (2018) Seafood consumption patterns, their nutritional benefits and associated sociodemographic and lifestyle factors among First Nations in British Columbia, Canada. Public Health Nutr 21(17): 32233236.

18. Schmedes M, Balderas C, Aadland EK, Jacques H, Lavigne C, et al. (2018) The Effect of Lean-Seafood and Non-Seafood Diets on Fasting and Postprandial Serum Metabolites and Lipid Species: Results from a Randomized Crossover Intervention Study in Healthy Adults. Nutrients 10(5).

19. Oyen J, Madsen L, Brantsæter AL, Skurtveit SO, Egeland GM (2019) Lean Fish Intake Decreases the Risk of Type 2 Diabetes Mellitus in Norwegian Women (P18-036-19). Curr Dev Nutr 3(1).

20. Afonso C, Bernardo I, Bandarra NM, Martins LL, Cardoso C (2019) The implications of following dietary advice regarding fish consumption frequency and meal size for the benefit (EPA + DHA and Se) versus risk (MeHg) assessment. Int J Food Sci Nutr 70(5): 623-637.

21. Rimm EB, Appel LJ, Chiuve SE, Djoussé L, Engler MB (2018) American Heart Association Nutrition 


\section{Advances in Clinical Toxicology}

Committee of the Council on Lifestyle and Cardiometabolic Health; Council on Epidemiology and Prevention; Council on Cardiovascular Disease in the Young; Council on Cardiovascular and Stroke Nursing; and Council on Clinical Cardiology. Seafood Long-Chain n-3 Polyunsaturated Fatty Acids and Cardiovascular Disease: A Science Advisory from the American Heart Association. Circulation 138(1): e35e47.

22. Zhao W, Tang H, Yang X, Luo X, Wang X, et al. (2019) Fish Consumption and Stroke Risk: A Meta-Analysis of Prospective Cohort Studies. J Stroke Cerebrovasc Dis 28(3): 604-611.

23. Bushkin-Bedient S, Carpenter DO (210) Benefits versus risks associated with consumption of fish and other seafood. Rev Environ Health 25(3): 161-191.

24. Sanchez-Villegas A, Alvarez-Perez J, Toledo E, SalasSalvado J, Ortega-Azorin C, et al. (2018) Seafood Consumption, Omega-3 Fatty Acids Intake, and LifeTime Prevalence of Depression in the PREDIMEDPlus Trial. Nutrients 10(12).

25. Yang Y, Kim Y, Je Y (2018) Fish consumption and risk of depression: Epidemiological evidence from prospective studies. Asia Pac Psychiatry 10(4): e12335.

26. Bakre AT, Chen R, Khutan R, Wei L, Smith T, et al. (2018) Association between fish consumption and risk of dementia: a new study from China and a systematic literature review and meta-analysis. Public Health Nutr 21(10): 1921-1932.

27. Gunnarsdottir I, Tomasson H, Kiely M, Martinez JA, Bandarra NM, et al. (2008) Inclusion of fish or fish oil in weight-loss diets for young adults: effects on blood lipids. Int J Obes (Lond) 32(7): 1105-1112.

28. Heilbronn LK, Smith SR, Ravussin E (2003) The insulin-sensitizing role of the fat derived hormone adiponectin. Curr Pharm Des 9(17): 1411-1418.

29. Liaset B, Oyen J, Jacques H, Kristiansen K, Madsen L (2019) Seafood intake and the development of obesity, insulin resistance and type 2 diabetes. Nutr Res Rev 32(1): 146-167.

30. Smith JD, Hou T, Ludwig DS, Rimm EB, Willett W, et al. (2015) Changes in intake of protein foods, carbohydrate amount and quality, and long-term weight change: results from 3 prospective cohorts. Am J Clin Nutr 101(6): 1216-1224.

31. (2017) Go Fish: For One of the Best Protein Foods For Bodybuilders.

32. Staff F (2008) Fish for Protein.

33. Dallas ME (2018) Could Eating Fish Boost Sex Lives and Fertility? Health Day News.

34. Gaskins AJ, Sundaram R, Buck Louis GM, Chavarro JE (2018) Seafood Intake, Sexual Activity, and Time to Pregnancy. J Clin Endocrinol Metab 103(7): 26802688.

35. Taylor CM, Emmett PM, Emond AM, Golding J (2018) A review of guidance on fish consumption in pregnancy: is it fit for purpose? Public Health Nutr 21(11): 2149-2159.

36. Chintagari S, Hazard N, Edwards G, Jadeja R, Janes M (2017) Risks Associated with Fish and Seafood. Microbiol Spectr 5(1).

37. Dickey RW (2012) FDA risk assessment of seafood contamination after the BP oil spill. Environ Health Perspect 120(2): a54-55.

38. Junaidi M, Krisnayanti BD, Juharfa, Anderson C (2019) Risk of Mercury Exposure from Fish Consumption at Artisanal Small-Scale Gold Mining Areas in West Nusa Tenggara, Indonesia. J Health Pollut 9(21): 190302.

39. Rahmani J, Fakhri Y, Shahsavani A, Bahmani Z, Urbina MA, et al. (2018) A systematic review and metaanalysis of metal concentrations in canned tuna fish in Iran and human health risk assessment. Food Chem Toxicol 118: 753-765.

40. Gao Y, Baisch P, Mirlean N, Rodrigues da Silva FM, Van Larebeke N, et al. (2018) Arsenic speciation in fish and shellfish from the North Sea (Southern bight) and Açu Port area (Brazil) and health risks related to seafood consumption. Chemosphere 191: 89-96.

41. Schmedes M, Brejnrod AD, Aadland EK, Kiilerich P, Kristiansen K, et al. (2019) The Effect of Lean-Seafood and Non-Seafood Diets on Fecal Metabolites and Gut Microbiome: Results from a Randomized Crossover Intervention Study. Mol Nutr Food Res 63(1).

42. Dong Z, Liang Z, Guo M, Hu S, Shen Z, et al. (2018) The Association between Plasma Levels of 


\section{Advances in Clinical Toxicology}

Trimethylamine N-Oxide and the Risk of Coronary Heart Disease in Chinese Patients with or without Type 2 Diabetes Mellitus. Dis Markers 2018: 1578320.

43. O'Mahony M (2018) EU Regulatory Risk Management of Marine Biotoxins in the Marine Bivalve Mollusc Food-Chain. Toxins (Basel) 10(3).

44. Mattarozzi M, Cavazza A, Calfapietra A, Cangini M, Pigozzi S, et al. (2019) Analytical screening of marine algal toxins for seafood safety assessment in a protected Mediterranean shallow water environment. Food Addit Contam Part A Chem Anal Control Expo Risk Assess 36(4): 612-624.

45. Farabegoli F, Blanco L, Rodríguez LP, Vieites JM, Cabado AG (2018) Phycotoxins in Marine Shellfish: Origin, Occurrence and Effects on Humans. Mar Drugs 16(6).

46. Wu H, Yao J, Guo M, Tan Z, Zhou D, et al. (2015) Distribution of Marine Lipophilic Toxins in Shellfish Products Collected from the Chinese Market. Mar Drugs 13(7): 4281-4295.

47. Alves RN, Rambla-Alegre M, Braga AC, Maulvault AL, Barbosa V, et al. (2019) Bioaccessibility of lipophilic and hydrophilic marine biotoxins in seafood: An in vitro digestion approach. Food Chem Toxicol 129: 153-161.

48. Barendse J, Roel A, Longo C, Andriessen L, Webster LMI, et al. (2019) DNA barcoding validates species labelling of certified seafood. Curr Biol 29(6): R198R199.

49. Chen KC, Zakaria D, Altarawneh H, Andrews GN, Ganesan GS, et al. (2019) DNA barcoding of fish species reveals low rate of package mislabeling in Qatar. Genome 62(2): 69-76.

50. Smith M, Love DC, Rochman CM, Neff RA (2018) Microplastics in Seafood and the Implications for Human Health. Curr Environ Health Rep 5(3): 375386.

51. Lusher A, Hollman P, Mendoza-Hill J (2017) Microplastics in fisheries and aquaculture: status of knowledge on their occurrence and implications for aquatic organisms and food safety. FAO Fisheries and Aquaculture Technical Paper 615: 147.
52. Hantoro I, Löhr AJ, Van Belleghem FGAJ, Widianarko B, Ragas AMJ (2019) Microplastics in coastal areas and seafood: implications for food safety. Food Addit Contam Part A Chem Anal Control Expo Risk Assess 36(5): 674-711.

53. Syron LN, Lucas DL, Bovbjerg VE, Kincl LD (2019) Injury and illness among onshore workers in Alaska's seafood processing industry: Analysis of workers' compensation claims, 2014-2015. Am J Ind Med 62(3): 253-264.

54. Nykjaer C, Higgs C, Greenwood DC, Simpson NAB, Cade JE, et al. (2019) Maternal Fatty Fish Intake Prior to and during Pregnancy and Risks of Adverse Birth Outcomes: Findings from a British Cohort. Nutrients 11(3).

55. Amezcua-Prieto C, Martínez-Galiano JM, SalcedoBellido I, Olmedo-Requena R, Bueno-Cavanillas A, et al. (2018) Maternal seafood intake and the risk of small for gestational age newborns: a case-control study in Spanish women. BMJ Open 8(8): 1-8.

56. Saher NU, Kanwal N (2019) Assessment of some heavy metal accumulation and nutritional quality of shellfish with reference to human health and cancer risk assessment: a seafood safety approach. Environ Sci Pollut Res Int 26(5): 5189-5201.

57. Furuya K, Nakajima H, Sasaki Y, Urita Y (2018) Anisakiasis: The risks of seafood consumption. Niger J Clin Pract 21(11): 1492-1494.

58. Friedman MA, Fernandez M, Backer LC, Dickey RW, Bernstein J, et al. (2017) An Updated Review of Ciguatera Fish Poisoning: Clinical, Epidemiological, Environmental, and Public Health Management. Mar Drugs 15(3).

59. Torris C, Smastuen MC, Molin M (2018) Nutrients in Fish and Possible Associations with Cardiovascular Disease Risk Factors in Metabolic Syndrome. Nutrients 10(7).

60. Gokoglu N (2019) Novel natural food preservatives and applications in seafood preservation: a review. J Sci Food Agric 99(5): 2068-2077.

61. Lemasson AJ, Hall-Spencer JM, Kuri V, Knights AM (2019) Changes in the biochemical and nutrient composition of seafood due to ocean acidification and warming. Mar Environ Res 143: 82-92. 